\title{
Evaluation of lodine Supplementation in Women With Pregnancy Associated With Gestational Diabetes. IODIAB Study
}

DURED DARDARI ( $\sim$ dured.dardari@gmail.com )

Centre Hospitalier Sud Francilien https://orcid.org/0000-0002-7172-4300

Francois-Xavier Laborne

Centre Hospitalier Sud Francilien

Caroline Tourte

Centre Hospitalier Sud Francilien

Elodie Henry

Centre Hospitalier Sud Francilien

Alfred Penfornis

Centre Hospitalier Sud Francilien

\section{Research Article}

Keywords: iodine, gestational diabetes, WHO, Health

Posted Date: November 17th, 2021

DOI: https://doi.org/10.21203/rs.3.rs-921852/v1

License: (a) (i) This work is licensed under a Creative Commons Attribution 4.0 International License. Read Full License 


\section{Abstract}

lodine supplementation is indicated by the French High Authority for Health (HAS) and by the World Health Organization (WHO) during pregnancy. We want to know if this supplementation is prescribed in a manner consistent with the HAS and WHO recommenations in women diagnosed with gestational diabetes mellitus.

\section{Results:}

Recruitment for the study will start August 2021 and will be ended in October 2021, with the final study results scheduled for December 2021

\section{Conclusion}

The objective of the lododiab study is to assess whether practitioners caring for women with gestational diabetes mellitus prescribe iodine supplementation according to the recommendations of the French High Authority for Health and by the World Health Organization.

\section{Introduction}

In pregnancy we observe (i) increasing in serum thyroxine-binding globulin (TBG) concentrations, (ii) an elevation in renal blood flow and glomerular filtration which lead to an increased iodide clearance from plasma and, hence, to an obligatory loss of iodine. (iii) Increased activity of type 3 deiodinase in the placenta increases the degradation of thyroxine $\left(T_{4}\right)$ to the inactive form reverse triodothyroinine $\left(T_{3}\right)$ [1]. Thyroid hormone is essential for neurodevelopment both in utero and early in life [2], severe iodine deficiency causes a range of disorders which include hypothyroidism, goiter and profound impairment of growth and neurodevelopmental [3], it is well established that correcting severe iodine deficiency leads to better clinical outcomes, including reduced cretinism and infant mortality rates [4], of late there are concerns increasingly that even mild to moderate iodine deficiency leads to adverse clinical outcomes, including potentially reduced intelligence quotient (IQ) in offspring $[5,6]$.

The physiological requirements for iodine are increased in pregnant women, going from $150 \mu \mathrm{g} /$ day to $250 \mu \mathrm{g} /$ day. The iodine intake is assessed by the iodine concentration in the urine, the target of which in pregnant women is ioduria between 150 and $250 \mu \mathrm{g} /$ I [7]. In French the general population is not deficient in iodine according to the national nutrition health study in 2006-2007, with a median ioduria of $136 \mu \mathrm{g} / \mathrm{I}$ (therefore greater than $100 \mu \mathrm{g} / \mathrm{I}$ ) for all elderly adults 18-74 years old [8], [9]. However, according to the French studies by Raverot et al., Luton et al. And Hieronimus et al, the median ioduria of pregnant women is between 50 and $100 \mu \mathrm{g} / \mathrm{I}$, which suggests a moderate iodine deficiency [10], [11], [12]. To maintain euthyroidism, the mother must increase its production of T4 by $40-50 \%(10-150 \%)$, which requires an additional iodine intake of $150-250 \mu \mathrm{g} / \mathrm{d}$ [13], [14], [15]. The thyroid contains a reserve of iodine, but this is depleted during pregnancy without supplementation. 
The world health organization (WHO), United Nations of International Children's Emergency Fund (UNICEF) international council for control of iodine deficiency disorders (ICCIDD) recommend a systematic iodine intake during pregnancy of at least $250 \mu \mathrm{g} /$ day. this supplementation should be facilitated by adding $150 \mathrm{\mu g} / \mathrm{d}$ of iodine to all polyvitamin and mineral preparations intended for pregnant women [16].

In another register, according to the WHO definition, gestational diabetes (GDM) is a disorder of carbohydrate tolerance leading to hyperglycemia of varying severity, beginning or diagnosed for the first time during pregnancy, from the diagnosis of GDM. it is assumed that the pregnant woman benefits from personalized care.

\section{Description And Rationale Of The Study Method}

The study protocol was approved by the French National Agency for Medicines and Health Products Safety (ANSM) and by the ethics committee of Agneres University Hospital (Institutional Review Board; Agreement of Department of Health and Human Services No. RCB : 2020-A02570-39) Comprehensive information on the study was provided to each patient on a form printed specifically for this purpose, the study received a registration on the clinical traial.gouve system with the number: NCT04683211

\section{STUDY OBJECTIVES}

\section{Main and secondary objectives:}

We wish to examine whether in women having a pregnancy benefiting from a personalized follow-up linked to a diagnosis of gestational diabetes, iodine supplementation is implemented according to WHO recommendations, ie $250 \mu \mathrm{g}$ / day. Primary Evaluation Criterion: Iodic supplementation prescribed in $\mu \mathrm{g} /$ d

Secondary objectives: evaluation of iodic supplementation according to prescriber (midwife versus general practician or gynecologist). Secondary evaluation criterion odic supplementation prescribed in $\mu \mathrm{g}$ / day by midwive, iodic supplementation prescribed in $\mu \mathrm{g}$ / prescribed by the general practitioner and iodic supplementation prescribed in $\mu \mathrm{g} /$ day by gynecologists.

\section{Participants}

Inclusion criteria: Pregnant woman with gestational diabetes confirmed by un abnormal fasting glucose or by oral hyperglycemia test, age $\geq 18$ years, subject informed of the study and not having opposed it. Non-inclusion criteria: Already known thyroid pathology.

\section{Key Data Collected and the outcome of the study}

Upon arrival at the reception consultation for the management of gestational diabetes, the information note will be given to the patient. During the consultation, the investigator will explain the study and obtain 
the patient's agreement to participate. The questionnaire will then be given to the patient.

There are no plans to follow up patients in this study. Participation consists of completing the questionnaire.

Data collected: The participants will answer to a questionary included the following questions: The term of pregnancy (in weeks), the parity (number of pregnancies), if the participants have a chronic pathology? If so, which one? which treatment? if the patient in known to have a pathology of the thyroid gland? If so, which therapy. Have the participant received a prescription for iodine supplementation since the start of pregnancy, If so, which one, for how long, at what dose. If there is iodic supplementation, who prescribed the prescription (midwife, attending physician, gynecologist. Are the lady receiving folic acid? During your previous pregnancies, did you receive vitamin supplementation? If yes which one?

\section{STATISTICAL methods}

Statistical justification for the sample size

We hypothesize that one in 2 patients receives iodine supplementation at $250 \mu \mathrm{g} / \mathrm{d}$. The number of patients is therefore 97 patients.

\section{Description of statistical methods}

The descriptive analysis will include for each quantitative parameter: mean, standard deviation, median, interquartiles, minimum, maximum. The qualitative parameters will be expressed by their number and corresponding percentage.

If $p$ is the expected percentage, its confidence interval, considered at $20 \%$, is: $p+-1.96$ * square root of ((p *(1-p) / n)

If $d$ is the distance between the estimate of the percentage and the bounds of its confidence interval, we must solve the equation:

$d=1.96 *$ square root of $((p *(1-p) / n)$

$=>n=1.96^{\wedge} 2 * p *(1-p) / d^{\wedge} 2 .=97$ patients

The analysis will be performed using R software (R version 3.5.0 (2018-04-23) @ 2018 The R Foundation for Statistical Computing).

\section{Discussion}

lodic supplementation during pregnancy is indicated according to the recommendations of the World Health Organization and by the high Health French authority, the main objective of the iodiab study is to assess whether the prescription of this supplement is respected by the wise. woman, the general 
practitioner and by the gynecologist who are supposed to offer a personalized follow-up for women with a diagnosis of pregnancy diabetes.

Recruitment for the iodiab study will start in August, the inclusion period is 3 months, the results will be published in December 2021

\section{Declarations}

Funding: Not applicable

Conflicts of interest: All authors declare that they have non conflicts of interest with the study

Competing interests: Not applicable

Availability of data and material: all data are available in the manuscript

Code availability: Not applicable

Authors' contributions DD and AP create the study and wrote the manuscript, FL, CT and EH contribute for collecting data, Formal analysis and investigation, alla authors approve the manuscript

Ethics approval: ethics committee of Agneres University Hospital (Institutional Review Board; Agreement of Department of Health and Human Services No. RCB : 2020-A02570-39)

Consent to participate and for publications: participated patients gave a written content to participate for the study and for the results publications

\section{References}

1. A.M. Leung, E.N. Pearce, L.E. Braverman lodine nutrition in pregnancy and lactation Endocrinol Metab Clin N Am, 40 (2011), pp. 765-777

2. Rovet, J.F. (2014) The role of thyroid hormones for brain development and cognitive function. Endocr Development, 26, 26- 43.

3. Zimmermann, M.B. (2009) lodine deficiency. Endocrine Reviews, 30, 376- 408.

4. Hetzel,B.S. (1983) lodine deficiency disorders (IDD) and their eradication. Lancet, 2, 1126- 1129.

5. Zimmermann, M.B. (2007) The adverse effects of mild-to-moderate iodine deficiency during pregnancy and childhood: a review. Thyroid, 17, 829- 835.

6. Taylor, P.N., Okosieme, O.E., Dayan, C.M. et al . (2014) Therapy of endocrine disease: Impact of iodine supplementation in mild-to-moderate iodine deficiency: systematic review and metaanalysis. European Journal of Endocrinology, 170, R1- R15.

7. World Health Organization, Geneva 2005 Prevention and control of iodine deficiency in pregnant and lactating women and in children less than two years old: conclusions and recommendations of the 
technical consultation Public Health Nutr, 10 (12A) (2007), pp. 1606-1611

8. Unité de surveillance et d'épidémiologie nutritionnelle, InVS, Université Paris 13Déficience en iode L'état de santé de la population en France - suivi des objectifs annexés à la loi de santé publique rapport [en ligne], Ministère des affaires sociales et de la santé, Direction de la recherche, des études, de l'évaluation et des statistiques, Paris (2011), pp. 144-145

9. World Health Organization, United Nations Children's Fund, International Council for the Control of lodine Deficiency Disorders 2007 Assessment of iodine deficiency disorders and monitoring their elimination. A guide for programme managers (3rd ed.), World Health Organization, Geneva (2007)

10. V. Raverot, C. Bournaud, G. Sassolas, J. Orgiazzi, F. Claustrat, P. Gaucherand, et al. Pregnant French women living in the Lyon area are iodine deficient and have elevated serum thyroglobulin concentrations Thyroid, 22 (5) (2012), pp. 522-528

11. D. Luton, C. Alberti, E. Vuillard, G. Ducarme, J.F. Oury, J. Guibourdenche lodine deficiency in Northern Paris area: impact on fetal thyroid mensuration PLoS One, 6 (2) (2011), p. e14707

12. S. Hiéronimus, M. Bec-Roche, P. Ferrari, N. Chevalier, P. Fénichel, F. Brucker-Davis Statut iodé et fonction thyroïdienne chez 330 femmes de la région niçoise évaluées en 2ème partie de grossesseAnn Endocinol, 70 (2009), pp. 218-224

13. International Council for the Control of lodine Deficiency Disorders lodine requirements in pregnancy and infancy ICCIDD Newsletter, 23 (2007), pp. 1-2

14. C. Bournaud, J. Orgiazzi Thyroïde et grossesse Ann Endocrinol, 64 (4) (2003), pp. 324-331

15. F. Delange lodine requirements during pregnancy, lactation and the neonatal period and indicators of optimal iodine nutrition Public Health Nutr, 10 (12A) (2007), pp. 1571-1580

16. EASTMAN CJ. Recommandation of a 2005 WHO Technical Consultation Group. 23th International Thyroid Congress, Buenos Aires, Argentina, 2005

\section{Supplementary Files}

This is a list of supplementary files associated with this preprint. Click to download.

- DUREDIODIABprotorniv1.020201006CTE2en.docx

- SPIRITChecklistdownload8Jan1311.doc 